\title{
Comment 1.1
}

FABIO MONTOBBIO

This project provides an extremely interesting comparison of research and technological transfer activities across different countries, and, in parallel, promotes the use of a set of metrics. The approach takes its departure from the analysis of the systems of innovation that encompasses the main actors and institutions involved in the process of knowledge transfer. It allows a fine-grained analysis of the different details of the context in which knowledge transfer takes place, exploiting a mixture of quantitative and qualitative analysis. In so doing, it provides a very valuable tool to help policymakers to measure the research, transfer, and commercialization activities in order to design new innovation policy approaches and sustain successful practices. On the one hand, it is important to learn about successful examples and best practices, and, on the other, efforts at emulation could have modest success if not coupled with deep attention to the underlying structural differences among the innovation systems of the different countries. Taking on board the systemic approach, I would like first to discuss my view on possible ways to disentangle the complexity of the different environments in which knowledge transfer takes place and, second, to discuss how normative statements can arise from this perspective. In particular, I would like to underline first how the different systems of innovation depend on a set of structural characteristics, namely: the intensity of the research effort, the technological specialization, and the industrial structures. Second, I would like to underline how systemic failures may occur at different levels, and fixing those failures naturally includes a quite heterogeneous set of policy interventions.

The first comment is that knowledge transfer practices are affected by a set of structural characteristics of the countries. So when addressing a comparison of knowledge transfer practices across countries, it is important to take into account the relative strengths and weaknesses of the public and private systems of R\&D. For example, it emerges that the 
six countries considered in this project have very different R\&D/GDP expenditures (OECD 2017a). In 2015 in China, the R\&D/GDP ratio was 2.1 percent, in Germany, 2.9 percent, in the Republic of Korea, 4.2 percent, in the United Kingdom, 1.7 percent, in Brazil, 1.2 percent, and, finally, in South Africa 0.7 percent. The growth of R\&D intensity has been impressive for China and Republic of Korea. For these countries the figures were 0.5 percent and 2.2 percent in 1995, respectively. It is also worth noting that the share of gross domestic expenditure on R\&D funded by the government is smaller in the Republic of Korea and China (21 percent and 23 percent, respectively, in 2015), denoting a relevant and increasing role of the R\&D funded by the private sector. In parallel, in Germany and the United Kingdom, the share of R\&D funded by the government is about 28 percent. This share for South Africa is 42 percent (OECD 2017b). For Brazil, UNESCO data show that in 2014 the investment in R\&D was BRL 65 billion, and almost two-thirds was funded by the government.

The figures given here show that countries like Brazil and South Africa that have a lower R\&D/GDP ratio are also the ones that display a weaker role for private sector $\mathrm{R} \& \mathrm{D}$. The relative role of the private sector, in turn, is associated with the profile of the country in terms of technological specialization and with processes of structural change. Technological capabilities tend to be associated to the technological specialization of countries. For example, Brazil and South Africa did not undertake a major process of structural change as China did. In China, a high growth in technological capabilities is associated with a substantial shift toward the electronic and telecommunications equipment industry and computers. These industries are a major driver of the aggregate growth of national and international patenting of the country (e.g., Malerba et al. 2011; Hu et al. 2017).

The distribution of technological capabilities in a country innovation system depends on the presence of different types of organization. In particular, it is important to have a balanced evolution of the different actors, with a growth of the presence of both multinational corporations and domestic innovators. China, for example, has a growing presence of both domestic and foreign companies in electronics. This confirms the major role played by ICT in the growth of the Chinese economy, as well as the role played by foreign companies in China. In parallel, the impressive growth of patenting activity at the Chinese Patent Office is mainly driven by new entrants: firms that were not systematically applying for patents in the past ( $\mathrm{Hu}$ et al. 2017). The dynamism of the domestic private sector witnesses the ability to absorb foreign knowledge and to 
benefit from the big investments in public institutions and infrastructures documented by Chapter 8 in this book.

An additional important aspect is the coherence between the technological activities of the different actors within the country innovation system. In Brazil and South Africa, universities and public research institutes tend to innovate and patent relatively more in chemicals, pharmaceuticals, and biotechnology. This presence has been growing over time and the Brazilian government has supported research in pharmaceuticals and biotechnology in both universities and public research institutes (see Chapter 7 of this volume and Ferrer et al. 2004). In parallel, the specialization profile of domestic multinational companies tends to remain stable in more traditional sectors such as consumer goods, engineering, and transport. Similar considerations could be put forward for South Africa. This potential mismatch between the activities of universities and public research institutes and the technological profile of the companies suggests that well-tuned knowledge transfer policies and practices are key for a balanced and sustainable path of growth (see Chapter 9).

Other structural aspects that might affect the way knowledge transfer takes place are the quality of the research system and the quality of the institutional framework. This book provides an excellent guide to assessing and comparing the complexities of the different countries. In particular it is worth noting that, in general, it is quite difficult to understand all the sources of public research funding in a country. Public funding passes through different levels of governance (e.g., state, regions, municipalities) and different types of organization (e.g., public/private/nonprofit/ foundations). There may be public research institutes that depend entirely on regional administrations or are owned by other public nonresearch entities. A quite heterogeneous set of government acts channels public money into knowledge transfer activities. All these countryspecific features affect the level of knowledge transfer activity but also the channels used and the quality of that transfer. For example, different public research intitutes may have different types of constraint in terms of patenting activity, and they may exploit the formal and informal channels of knowledge transfer to different degrees (see, for example, the discussion in the chapters on Germany and the UK in Chapters 5 and 4 , respectively).

Finally, geographical aspects play an important role. The presence of innovative geographically concentrated clusters could provide, on the one hand, specific agglomeration effects and, on the other, regional 
imbalances. Knowledge transfer practices may vary dramatically according to whether companies and universities and public research institutes are colocated in a technological cluster or in a science park or whether the region is characterized by the prevalence of rural areas.

My second comment discusses how normative statements can arise from this perspective, and I would like to underline that a precise qualitative and qualitative description of the systems of innovation shows where the successes and the potential failures of the processes and practices of knowledge transfer actually are. This book addresses the issue of knowledge transfer with a broad view that institutions and regulations are constitutive elements of the innovation system. In particular, a substantial effort of the different studies is dedicated toward understanding the different specific regulations that different countries adopted. These regulations generate the specific conditions under which firms, individuals, universities, and public research institutes own immaterial assets and the new knowledge they produce. These regulations should create incentives to invest in new knowledge and in parallel facilitate diffusion and commercialization. It is emphasized that the process of knowledge transfer is characterized by a set of formal and informal channels, and these channels depend on different types of regulation: hard regulations and soft regulations (Borrás and Edquist 2014). Soft regulations are not legally binding and hard regulations are a set of rules with some mechanism for monitoring and promoting compliance with the rules.

So systemic failures may take place at different levels, and fixing those failures naturally includes a quite heterogeneous set of policy interventions. The interesting aspect is how to frame precisely normative issues with this approach. Actually, the approach is very flexible and allows, through detailed case studies, the identification of specific problems in the innovation system that could unfold at different levels. For example, at the policy level it is difficult in many cases to be able to clearly argue whether there is the need for more R\&D or more knowledge transfer (or more knowledge transfer offices) or more university-industry cooperation. In many cases, knowledge transfer policies are simply imported from other countries without a precise understanding of the bottlenecks in the system (Ejermo and Toivanen 2018). However this approach beyond simple policy prescriptions on market failures - allows us to identify different types of specific failure and problem in the system and allows for the identification of specific policy answers (Edquist 2011). 
This book provides many different examples of potential design failures, network failures, or capability failures. Design failures occur when a regulation generates incentives that are not compatible with the policy objective; network failures happen because of a lack of linkages between actors. This creates a weak exploitation of complementarities and learning. We observe a network failure also when firms and companies in a country are tightly connected but remain locked in and miss out on new outside developments. Capability failures take place when firms, universities, public research institutes, and, in particular, KTOs lack the capabilities to learn rapidly and effectively and hence remain locked into existing practices. This conceptual framework therefore provides detailed guidance on how to evaluate existing knowledge transfer policies, practices, and outcomes, to identify in a comparative way potential failures and problems, and, finally, to design specific targeted policy intervention.

\section{References}

Borrás, S. and C. Edquist (2014). Institutions and Regulations in Innovation Systems: Effects, Problems and Innovation Policy Design. CIRCLE Working Paper 2014/29. Lund University, Sweden.

Edquist, C. (2011). "Design of innovation policy through diagnostic analysis: Identification of systemic problems (or failures)." Industrial and Corporate Change, 20(6): 1-29.

Ejermo, O. and H. Toivanen (2018). "University invention and the abolishment of the professor's privilege in Finland." Research Policy, 47(4): 814-25.

Ferrer, M., H. Thorsteinsdóttir, U. Quach, P.A. Singer, and A. S Daar (2004). “The scientific muscle of Brazil's health biotechnology.” Nature Biotechnology, 22, Supplement December: DC8-DC12.

Hu, A.G.Z., P. Zhang, and L. Zhao (2017). "China as number one? Evidence from China's most recent patenting surge.” Journal of Development Economics, 124: 107-19.

Malerba, F., F. Montobbio, and V. Sterzi (2011). The Growth and Evolution of Advanced Technological Capabilities in the Main Emerging Countries. Patent analysis, presented at the 9th Globelics International Conference.

OECD (2017a). OECD Science, Technology and Industry Scoreboard 2017: the Digital Transformation. Paris: OECD. http://dx.doi.org/10.1787/9789264268821-en.

OECD (2017b). Main Science and Technology Indicators, Vol. 2017 Issue 1. Paris: OECD. http://dx.doi.org/10.1787/msti-v2017-1-en. 